\title{
An approach to achieve overall farm feed efficiency in pig production: environmental evaluation through individual life cycle assessment
}

\author{
Tara Soleimani $^{1}$ (D) $\cdot$ Helene Gilbert $^{1}$
}

Received: 7 July 2020 / Accepted: 22 December 2020

(c) The Author(s) 2021, corrected publication 2021

\begin{abstract}
Purpose Use a holistic individual life cycle assessment (LCA) to investigate possible mitigation of environmental impacts through optimisation of overall farm feed efficiency by combining animal selection for feed efficiency and formulation of diets with minimum environmental impacts tailored to pig nutritional requirements.

Methods A linear multi-objective optimisation method was used to combine diet optimisation tailored to meet the representative nutritional requirements of genetic lines with environmental optimisation of the environmental impacts of the diet. Environmental optimisation was obtained by weighting the environmental impacts of the diet in a single environmental impact score. An individual trait-based LCA model with a cradle-to-farm-gate system boundary and functional unit of $1 \mathrm{~kg}$ live pig at the farm gate was applied to genetic lines selected for high (LRFI, high feed efficient line) and low (HRFI, low feed efficient line) feed efficiency data. The production traits of each individual animal in response to the optimised diets were simulated with InraPorc $®$ and imported into the individual LCA model to assess global warming potential (GWP), terrestrial acidification potential (AP), freshwater eutrophication potential (EP), and land occupation (LO) of the overall farm feed efficiency approach. Results and discussion Integrating selection for feed efficiency, nutritional requirements of genetic lines (HRFI and LRFI) and environmental diet optimisation resulted in overall mitigation of environmental impacts. Compared to the conventional diet, the environmental score of the optimised tailored diets was reduced by 5.8\% and 5.2\% for LRFI and HRFI lines, respectively. At the general production system level, the environmental impacts decreased by an average of $4.2 \%$ for LRFI and 3.8\% for HRFI lines compared to environmental impacts of the lines fed the conventional diet $(P<0.05)$. The HRFI line with its optimised tailored diet had fewer impacts than the LRFI line with the conventional diet, except for EP. Individual LCA revealed high correlations between environmental impacts and feed efficiency and protein deposition traits.

Conclusions Implementation of overall farm feed efficiency would effectively mitigate environmental impacts. A holistic economic evaluation of the resulting trade-off between diet costs and pig performances is now needed to design a comprehensive tool to orientate selection and formulation decisions for sustainable pig production systems.
\end{abstract}

Keyword Environmental impact $\cdot$ Life cycle assessment $\cdot$ Residual feed intake $\cdot$ Feed efficiency $\cdot$ Nutrient tailored diet $\cdot$ Diet environmental optimisation $\cdot$ Pig

\section{Introduction}

Improving feed efficiency is a major objective to enhance pig production sustainability in terms of economy and environment. The main environmental impacts of pig

The original online version of this article was revised due to an error in figure 4.

\section{Communicated by Thomas Jan Nemecek.}

Tara Soleimani

tara.soleimani@inrae.fr

1 GenPhySE, Université de Toulouse, INRAE, F-31326

Castanet-Tolosan, Toulouse, France production originate from feed production (Opio et al. 2013) and from manure excretion and emissions during pig farming (Dourmad and Jondreville 2007; Mackenzie el al. 2016). The improvement in the main environmental burden sources can be obtained through reduction in feed intakes, and supply of nutrients tailored to the animal requirements, to achieve better use of lower quantities of feed by the animals. Feed efficiency, which is usually expressed as its inverse, feed conversion 
ratio (FCR), stands for the body weight gain per unit of feed consumed. Selecting pigs based on feed conversion ratio (FCR) or residual feed intake (RFI) has been shown to be effective to improve feed efficiency in growing pigs (Gilbert et al. 2007 and 2017; Cai et al. 2008; Rothschild and Ruvinsky 2011). Unbalanced dietary nutrients and energy in the feed ration can result in unnecessary high excretion rate. Thus, a diet tailored to nutritional requirements is an important aspect for the environmental optimisation of pig production (Hauschild et al. 2012; Pomar and Remus 2019). Improving feed efficiency by adjusting the composition of the diet to the nutritional requirements of a group or an individual animal (precision feeding) has also been investigated (Pomar et al. 2009; Remus et al. 2019; Monteiro et al. 2017), and some related methods, decision support tools, and systems are under development (Brossard et al. 2017 and 2019). Other methods are available for environmental diet optimisation either by accounting for the choice of ingredients to be incorporated (Garcia-Launay et al. 2018; Tallentire et al. 2017) or combining diet optimisation with minimum nutrient excretion impacts (Mackenzie et al. 2016). Life cycle assessment (LCA) has already been used for environmental assessment of various aspects of pig production systems (Lammers. 2011; Garcia-Launay et al. 2014; Mackenzie et al. 2015; McAuliffe et al. 2016 and 2017; Ottosen et al. 2019). We assessed the environmental impacts of pig selection for feed efficiency in a previous study by using individual LCA (Soleimani and Gilbert 2020), which made it possible to link individual genetic profiles to individual environmental impacts. Here, we propose an overall environmental optimisation approach for pig production which combines 'pig selection for feed efficiency', 'formulation of a nutritionally tailored diet' and 'environmental optimisation of the diet' as a strategy to achieve an overall farm feed efficiency. To achieve overall farm feed efficiency, diets were formulated according to the nutritional requirements of lines selected for different feed efficiency levels. Given these constraints, diets with minimum environmental impacts were determined, and the resulting environmental impacts of a system combining selected lines fed their optimised tailored diet were quantified to assess overall farm feed efficiency. The aim of this study was to establish the optimisation model and assess the total environmental impacts of improvements in overall farm feed efficiency on pig production, by performing individual LCA. The performance traits correlated with the environmental impacts could then use for further pig selection choices for environmental objectives.

\section{Materials and methods}

\subsection{LCA}

Environmental impacts were evaluated using life cycle assessment (LCA), which is most frequently used to assess the environmental impacts of products and services (Itskos et al. 2016). The marked contribution of emissions during animal farming, manure storage and application, quantified as global warming potential (GWP), acidification potential (AP), and eutrophication potential (EP) (de Vries and de Boer 2010), have massive implications on human health and ecosystems. Thus, these three impact categories are the most common in LCA studies of pig production (McAuliffe et al. 2016). In addition, since vast land areas are required for producing ingredients for feed, relatively to those for vegetable protein and oil (Basset-Mens et al. 2005), some being located in sensitive ecosystems exposed to high land conversion rate, the land occupation impact category is important for an environmental impact assessment of pig production. Consequently, the impact categories GWP $\left(\mathrm{kg} \mathrm{CO}_{2}\right.$-eq), $\mathrm{AP}$ ( $\mathrm{kg} \mathrm{SO}_{2}$ eq), EP ( $\left.\mathrm{kg} \mathrm{P} \mathrm{eq}\right)$, and $\mathrm{LO}\left(\mathrm{m}^{2} \mathrm{a}\right.$ crop eq) were used to assess the environmental impacts in our study ReCiPe Midpoint 2016 (H) V1.02 (Huijbregts et al., 2017), was used together with Ecoalim (Wilfart et al. 2016) and Ecoinvent (Wernet et al. 2016) inventory databases for the impact assessment. Individual environmental assessments for each pig were implemented in SimaPro V8.5.4.0 on the MEANS (MulticritEria AssessmeNt of Sustainability) platform (http://www.inra.fr/means), following the approach we proposed in a previous study (Soleimani and Gilbert 2020).

\subsubsection{Goal and scope}

The goal of the present study was to develop an approach to achieve overall farm efficiency in pig farms, and to investigate the resulting environmental impacts using a trait-based individual LCA model (Soleimani and Gilbert 2020). A 'cradle-to-farm-gate' system boundary including feed production, sow-litter, post-weaning, fattening pigs and manure management, was taken from conventional French pig farming systems. A simplified process flow diagram of the system is shown in Fig. 1. One kilogram of pig live weight (LW) at the farm gate was chosen as the functional unit, and used as a reference to compare the environmental impacts of the different scenarios.

\subsubsection{The LCA model}

The LCA model was developed in six separate modules: feeding plan, animal profile, emissions, excretion, water expenditure and energy expenditure (Soleimani and Gilbert 2020). Briefly, the model was developed based on pig net energy (NE) requirements, with a focus on the fattening period to allow prediction of the different performance profiles resulting from the composition of the tested diet. InraPorc $\AA$ software, designed to simulate the performance pigs' response to different nutritional strategies (van Milgen et al. 2008; Dourmad et al. 2008), was incorporated in the 


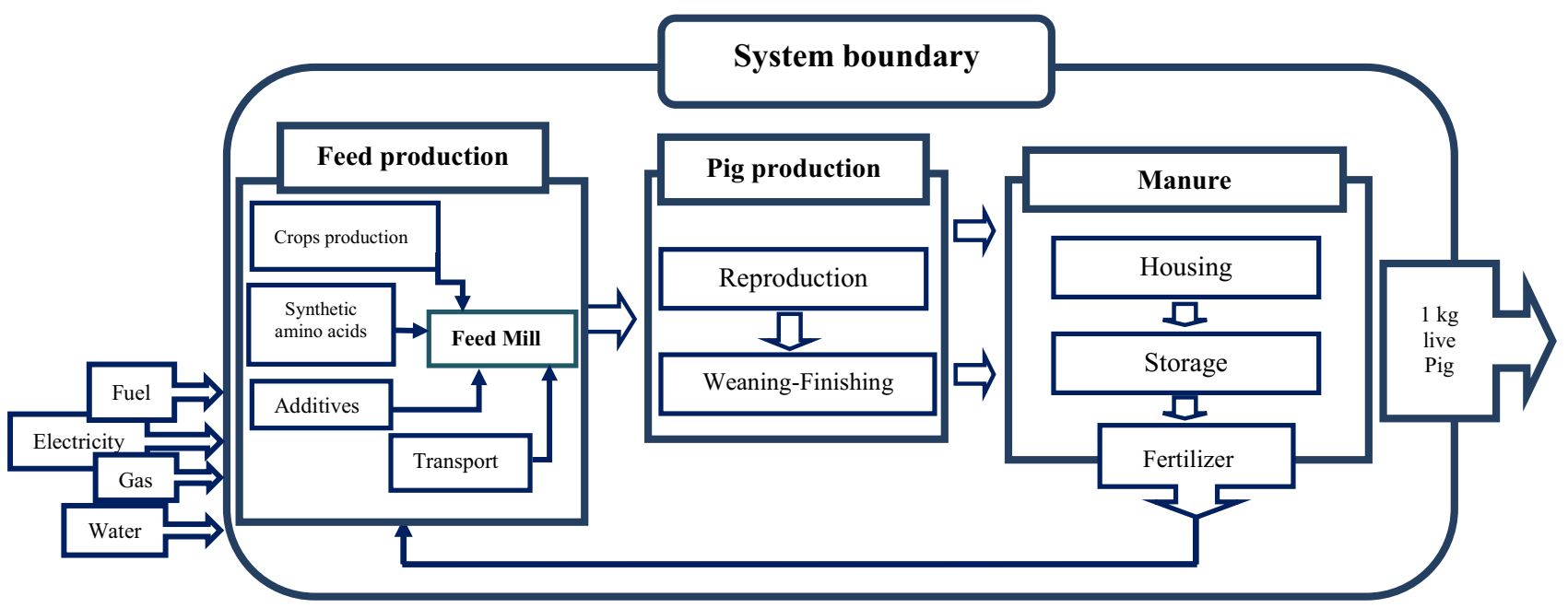

Fig. 1 Scheme of the system boundary, which includes the entire pig farm, feed production processes and manure management

LCA model to obtain sow-litter profiles (identical in all scenarios), feeding plans and corresponding simulated growth performance during fattening. Water and energy expenditures were calculated based on the IFIP report on typical French farms (IFIP-Institut de la Filière porcine 2014). The individual fattening performance traits were used as input parameters in the life cycle inventory (LCI) in SimaPro to perform individual LCAs. The components of excreta (dry matter (DM), organic matter $(\mathrm{OM})$, nitrogen $(\mathrm{N})$, phosphorus $(\mathrm{P})$ and potassium $(\mathrm{K})$ ) were calculated using the mass-balance approach, as the difference between nutrient intake in the feed and the nutrients retained in the body (Supplementary Material S1). A typical French slatted floor type of housing and slurry storage was adopted, along with system expansion approach considering that the manure produced replaced a certain percentage of mineral fertilisers (Garcia-Launay et al. 2014). Average performance data were used for the sow-litter stage, and individual performance data were used for the postweaning and fattening stages. Emissions of enteric methane $\left(\mathrm{CH}_{4}\right)$, nitrous oxide $\left(\mathrm{N}_{2} \mathrm{O}\right)$, nitrogen $\left(\mathrm{N}_{2}\right)$ and ammonia $\left(\mathrm{NH}_{3}\right)$ in the building and during outside storage were calculated according to the IPCC guidelines (Tier I and Tier II) using model and emission factors developed by Rigolot et al. (2010a and 2010b) for French pig systems. Methane emissions from manure during storage, emissions of $\mathrm{N}_{2} \mathrm{O}$, were calculated using the guidelines provided by the intergovernmental panel on climate change IPCC (2006, Tier 2) and the potential leaching rate of $\mathrm{PO} 4$ and $\mathrm{NO} 3$ during spreading of slurry were adopted from Nguyen et al. (2012). $\mathrm{NO}_{x}$ emissions were calculated according to Nemecek et al. (2004). The fertiliser equivalence value of the manure as a replacement for synthetic fertiliser was considered to be $100 \%$ for $\mathrm{P}$ and K (Nguyen et al. 2011) and 75\% for N (Nguyen et al. 2010).
To ensure the results were comparable, the inventories, methods and calculations were kept the same in all the LCA runs. The environmental impacts of the diet ingredients were obtained from the Ecoalim dataset (Wilfart et al. 2016) of the AGRIBALYSE $\AA$ database using the Recipe method 2016, applying the attributional approach. Values of $500 \mathrm{~km}$ for cereals and $100 \mathrm{~km}$ for meals were used for the transport of ingredients from the farm to the feed factory (GarciaLaunay et al. 2018), and a value of $30 \mathrm{~km}$ (Cadéro et al. 2018) was used for the distance from the feed factory to the pig farm, taken from the attributional life cycle inventories of the ecoinvent version 3.1 database.

\subsection{Experimental data}

Experimental data (body weights, feed intakes, body composition) were available from birth to slaughter weight for two lines of Large White pigs divergently selected for RFI under ad libitum feeding with the conventional diet. The composition of the conventional diet is reported in the Supplementary Material S2. The selection process concerning low RFI (LRFI, more efficient pigs) and high RFI (HRFI, less efficient pigs) lines are reviewed in Gilbert et al. (2017). The dataset used in the present study included data from 57 male pigs of the fifth generation of each line fed a conventional diet formulated to cover pig requirements. Growing pigs had ad libitum access to a onephase conventional diet from 10 weeks of age to slaughter (at about $115 \mathrm{~kg}$ body weight). The data on individual daily feed intake (DFI) for the whole fattening period were recorded on automatic feeders (ACEMO, Pontivy, France), and back fat thickness (BFT) was measured via ultrasounds on live animals at 23 weeks of age, using an echograph (ALOKA SSD-500, Cergy Pontoise, France). Average 
daily gain (ADG), feed conversion ratio (FCR), and RFI were then computed as reported in Gilbert et al. (2007). The experimental data for reproductive sows and litters of the same lines (LRFI and HRFI) including the mean sow and piglet BW at weaning and farrowing, sow BFT before farrowing, sow lactation DFI, number of total born, still born and weaned piglets, piglet BW at birth and at weaning, and farrowing and weaning age, were adopted from Gilbert et al. (2012).

\subsection{Line diet optimisation}

In this study, the diet formulation was optimised to obtain diets with minimum environmental impacts but covering the specific nutritional requirements of the different genetic lines. To diversify the sources of energy and protein available for the diet formulation, six ingredients, oats, triticale, corn, peas, rapeseed meal, and sunflower meal were added to the eight ingredients of the conventional diet (barley, wheat, soybean meal, sunflower oil, and synthetic AA L_ lysine (LLY), L_threonine (LTH), L_tryptophan (LTR), DL_ methionine (DLM)), to formulate new diets. The new ingredients were selected based on their availability at the market and on the accessibility of their characterization data in the embedded database of InraPorc ${ }^{\circledR}$. The net energy (NE) density and digestible $\mathrm{CP}$ and AAs of the ingredients were extracted from the INRA-AFZ database (Sauvant et al. 2004) of feed ingredients (Table 1). Ingredients like salt, carbonate calcium and vitamins, which do not have digestible energy, $\mathrm{CP}$ or AAs, were considered as additives and excluded from the formulation step, so in total $Q=14$ ingredients were retained for formulation. Some common industrial rules and recommendations for commercial diet formulation, such as storage availability, are beyond the scope of this study and are not accounted for.

\subsubsection{Choice of nutritional requirements for diet formulation}

To formulate a diet tailored to animal dietary requirements, the nutritional constraints which should be satisfied by the diet have to be identified. Pigs adjust their ad libitum feed intake to the net energy density (NE) of the diet (Quiniou and Noblet 2012). Consequently, dietary nutrients are up taken proportionally to the NE of the diet. In cereal-based diets, essential amino acids (AA) lysine, threonine, tryptophan, and methionine are the most limiting AA (D'Mello. 1993), which turned out to be mostly added as synthetic AA to cereals to achieve balanced nutritional composition, as in the conventional diet used to obtain the pig performances in our previous study (see Table 1, Soleimani and Gilbert 2020, for details). Thus, to avoid AA deficiency, these four amino acids were set as target constraints in the formula- tion. In addition, to satisfy the dietary requirements of all amino acids, crude protein (CP) was also set as a target constraint to ensure coverage of the remaining essential and non-essential amino acids. Finally, digestible CP and AA requirements were standardised to the $\mathrm{NE}$ content of the diet, to account for the feed intake regulation by NE density. Therefore digestible crude protein $(\mathrm{CP})$, digestible lysine, digestible threonine, digestible tryptophan, and digestible methionine, expressed as standardised requirements to the diet NE (g/MJ NE), were retained as the target constraints to be satisfied by the diets tailored to the pig requirements.

\subsubsection{Determination of the representative nutritional requirements of the lines}

The experimental data were imported into InraPorc ${ }^{\circledR}$ to calibrate a growth performance profile for each individual pig. The profiles were calibrated using the recorded daily ad libitum feed intake during the fattening period with the conventional diet, expressed relative to the NE of the diet. The individual digestible $\mathrm{CP}$ and AA requirement profiles of the pigs were then obtained as InraPorc $®$ outputs. Pigs are usually fed in groups with a single diet adjusted to the nutrient requirements of a representative pig in the group (Remus et al. 2019). Accordingly, the five targeted daily requirements for the whole fattening period were extracted from InraPorc ${ }^{\circledR}$ for each individual to identify the representative pig for each line in our dataset. For all individuals, the maximum requirements for these five indicators were observed in the early stages of the growing period. From these individual maxima, the mean maximum requirement for each line was computed for each indicator as the representative requirement of each line. In the following, Alpha is the digestible crude protein requirement ( $\mathrm{g}$ per MJ NE), Beta is the digestible lysine requirement (g per MJ NE), Gamma is the digestible threonine requirement (g per MJ $\mathrm{NE}$ ), Lambda is the digestible methionine requirement ( $\mathrm{g}$ per MJ NE), and Delta is the digestible tryptophan requirement (g per MJ NE).

\subsubsection{Diet formulation tailored to each line}

To consider the representative requirement of each line in the tailored diet formulation, linear Eqs. (1-6) were retained as constraints for each line $l$ ( $l=2$ in our study) and $Q$ possible ingredients ( $Q=14$ in our study). Since the diet would be formulated for $1 \mathrm{~kg}$ of feed, the first equation ensures the prospective diet plus the additives does not exceed one $\mathrm{kg}$, and the rest of the equations ensure the dietary nutrients correspond to the representative requirements of each line.

$1 \mathrm{~kg}-$ additives $(\mathrm{kg})=\sum_{i=1}^{Q} q_{i_{l}}$ 


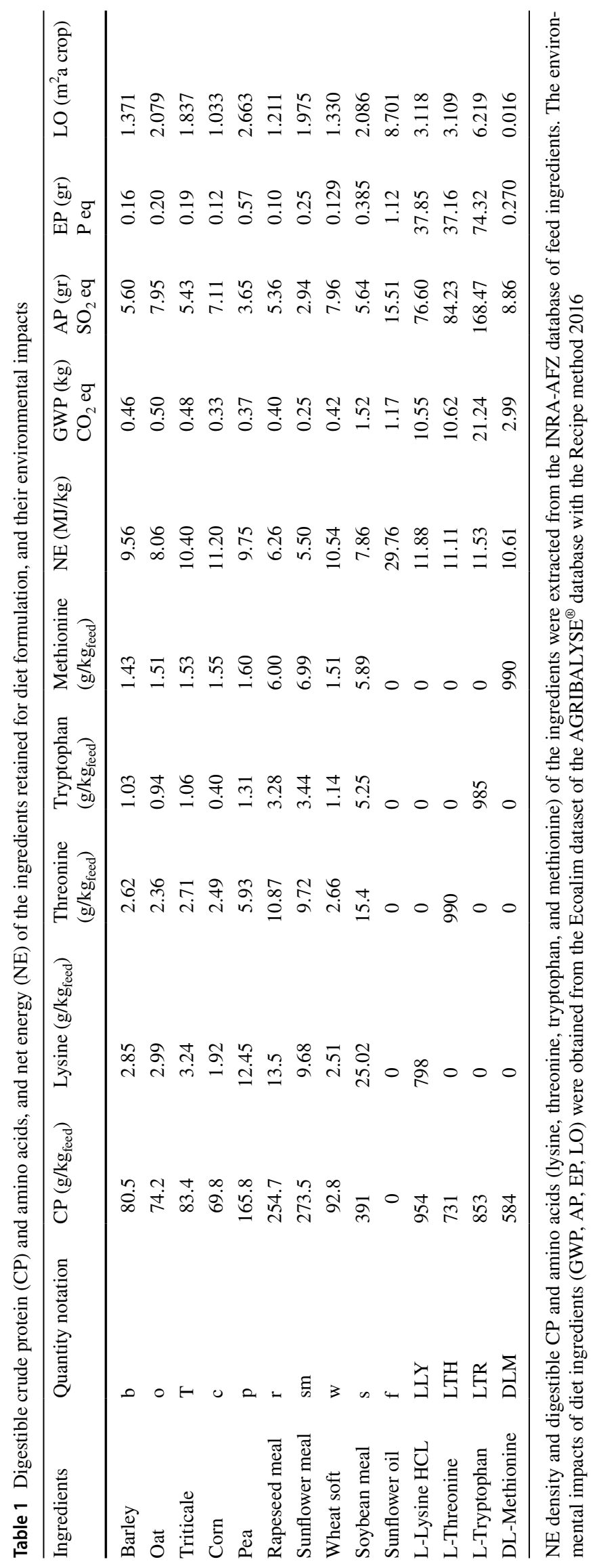




$$
\begin{aligned}
& \text { Alpha }_{l}=\sum_{i=1}^{Q} q_{i_{l}} C P_{i} / \sum_{i=1}^{Q} q_{i_{l}} N E_{i} \\
& \text { Beta }_{l}=\sum_{i=1}^{Q} q_{i} L L Y_{i} / \sum_{i=1}^{Q} q_{i_{l}} N E_{i} \\
& \text { Gamma }_{l}=\sum_{i=1}^{Q} q_{i_{l}} L T H_{i} / \sum_{i=1}^{Q} q_{i_{l}} N E_{i} \\
& \text { Delta }_{l}=\sum_{i=1}^{Q} q_{i_{l}} \text { LTR }_{i} / \sum_{i=1}^{Q} q_{i_{l}} N E_{i} \\
& \text { Lambda }_{l}=\sum_{i=1}^{Q} q_{i_{l}} D L M_{i} / \sum_{i=1}^{Q} q_{i_{l}} N E_{i}
\end{aligned}
$$

\subsubsection{Formulating tailored diets with minimum environmental impacts for each line}

The least environmental impact formulation approach implemented in this study involves two steps: (1) formulating a least cost (LC) diet as the baseline reference for environmental impacts and cost, and (2) formulating a diet with the lowest environmental impact score in an acceptable cost interval compared to the least cost diet. In step 1, the objective function of the optimisation is the cost, which should be minimised conditionally to the nutritional constraints in Eqs. (1)-(2). For the nutritional constraints, the cost constraint was normalized to the ingredient NE to compute the diet cost to minimise:

$\min \cos t=\sum_{i=1}^{Q} q_{i_{l}} p_{i} / N E_{i}$

where $q_{i_{1}}, p_{i}$ and $N E_{i}$ are the rate of incorporation of the $i$ th ingredient in line $l$, the price and net energy of $i$ th ingredient, respectively, with $i=1, \ldots, Q$. The least cost diet for each line was obtained through an evolutionary optimisation algorithm of NSGA-II from Eqs. (1)-(2) with library of mco in $\mathrm{R}$ version 3.6.3 (population size of 340 and 3500 generations). This algorithm identifies the non-dominated solutions on the Pareto-optimal front curve that best satisfy the nutritional and cost constraints. The price of each ingredient was obtained from the monthly average of the market price of ingredients in France reported by IFIP (IFIP, Mensuel d'information aliment, May 2020). The environmental impacts of the least cost diet $\left(\mathrm{GWP}_{L C}, \mathrm{AP}_{L C}, \mathrm{EP}_{L C}, \mathrm{LO}_{L C}\right)$ for each line $l$ were calculated by summing the environmental impacts of each ingredient (Table 1) in proportion to its rate of corporation in the diet: impact $_{L C_{l}}=\sum_{i=1}^{Q} q_{i_{l}}$ impact $_{i}$

where impact $_{i}$ is the environmental impact of ingredient $i$, and impact is GWP, AP, EP, or LO.

For step 2, the first task was to define an environmental impact score to minimise. The environmental impacts of the least cost diet were used for each line as normalization factors for each impact, as proposed by Garcia-Launay et al. (2018). Then, weights were applied to obtain an environmental impact score (EI score) to minimise as a new objective function:

$\mathrm{EI}_{\text {scorel } l}=\sum_{\text {impact }=1}^{4} w_{\text {impact }}\left(\left(\sum_{i=l}^{Q} q_{{ }_{i}}{ }_{i_{l}}\right.\right.$ impact $\left._{i} / N E_{i}\right) /\left(\right.$ impact $\left.\left._{L C_{l}}\right)\right)$

where $q^{\prime}{ }_{i_{l}}$ is the quantity of $i$ th ingredient in the diet with the lowest environmental impact score for line $l$. In our study, an equal weighting of one was first used for $w_{G W P}$, $w_{E P}, w_{A P}$, and $w_{L O}$ to avoid unbalanced impacts of the environmentally optimised tailored diet. Finally, the costs of the least environmental score diets were limited to avoid exceeding the cost of the least cost diet by more than $10 \%$. The NSGA-II algorithm was applied to obtain the diets with the lowest environmental impact score under the dietary requirement constraints for each line, from Eqs. (1)-(2) and (3) with cost $<110 \%$ least cost.

\subsubsection{Sensitivity analysis of the environmental impacts of the diets to the representative requirements of the lines and environmental score weights}

To define an approach to assess the sensitivity of the environmental impacts of the diets to changes in the representative requirements of the lines, first the correlations between the individual maximum requirements of the pigs in each line were computed. All the representative requirements were highly correlated $(>0.99)$. To consider these high correlations in a sensitivity analysis, an all-at-once sensitivity analysis was conducted based on changes in all the requirements combined, first for +1 standard deviation (SD), and then for $-1 \mathrm{SD}$, separately for the two lines. Then, the full diet optimisation process described above was applied again, and the differences in the environmental impacts of the new optimised tailored diet relative to the initial optimised tailored diet were used for within-line sensitivity analysis. An impact category was considered to be sensitive to changes in the representative requirements of the line if the change in that impact category was greater than 5\% (Mackenzie et al. 2016) due to changing by $+1 \mathrm{SD}$ or $-1 \mathrm{SD}$ all the representative requirements of the lines at once. In addition, in the environmental score used for optimisation, the 
environmental impact weights ( $\mathrm{w}_{\mathrm{GWP}}, \mathrm{w}_{\mathrm{EP}}, \mathrm{w}_{\mathrm{AP}}$ and $\mathrm{w}_{\mathrm{LO}}$ ) were equal to 1 . To assess the sensitivity of optimised tailored diet environmental impacts to the choice of weight, a one-at-a-time sensitivity analysis was performed based on successive changes of +0.5 and -0.5 for each weight in each diet optimisation run, separately for the two lines.

\subsection{Environmental evaluations of overall farm feed efficiency}

The growth performance traits, including average daily feed intake, average daily gain, back fat thickness, body protein and body lipid at slaughter $(120 \mathrm{~kg})$ and length of the fattening period, were simulated with InraPorc ${ }^{\circledR}$ for each pig in response to its line optimised tailored diet. These performances were then used as input parameters for the individual trait-based LCA mode (Soleimani and Gilbert 2020) to assess the environmental impacts of the overall farm feed efficiency approach. Statistical analyses were applied to the outputs of the different steps of this evaluation, based on calculation of the line means and SDs of growth performance traits and their environmental impacts. $t$ Tests were used to test the line differences, and environmental impacts were declared significantly different between scenarios when $P<0.05$. Correlations between traits and environmental impacts were performed to identify the traits with maximum environmental impact. In addition, a principal component analysis was also performed for a better understanding of the relationships between the components (using fviz function from library of factoextera in R).

\section{Results}

\subsection{Representative requirements of the lines based on individual requirements}

Table 2 lists the means and standard deviations of the five representative requirements of the two genetic lines (digestive $\mathrm{CP}$, lysine, threonine, methionine and tryptophan). On average, the LRFI line had $+5 \%$ requirements in $\mathrm{g} / \mathrm{MJ} \mathrm{NE}$ compared to the HRFI line $(P<0.05)$, with the crude protein requirements showing the largest difference (6.4\%) between lines.

\subsection{Environmentally optimised diets tailored to the nutritional requirements of each line}

The least environmental impact score diet which satisfies the representative requirements of each line at a cost less than $110 \%$ of that of the least cost diet was retained as the optimised tailored diet for the corresponding line. The LRFI optimised tailored diet had 9.38 MJ NE/kg, and the HRFI optimised tailored diet had 9.75 MJ NE/kg, with triticale, in which the proportions of sunflower meal and soybean meal were highest in the LRFI optimised tailored diet, whereas pea and sunflower oil were incorporated only in the HRFI optimised tailored diet (Supplementary Material S3). In addition, smaller quantities of synthetic AA were incorporated in the LRFI optimised tailored diet (L-tryptophan and DL-methionine), whereas L-lysine was higher in this diet. Compared to their respective least cost diets with the 9.27 MJ NE/kg for LRFI and 10.01 MJ NE/ $\mathrm{kg}$ for HRFI, the main differences in composition were in triticale, wheat, sunflower meal and corn along with less incorporation of L-Lysine in HRFI optimised tailored diet. Table 3 lists the environmental impacts and cost of the line optimised tailored diets and least cost diets, together with the conventional diet. The environmental impact score of the optimised tailored diets decreased of $-5.2 \%$ for HRFI and $-5.8 \%$ for LRFI compared to the score of conventional diet, as the feed cost per MJ NE $(-11.5 \%$ and $-12.0 \%$ ). When considering the detailed $\mathrm{E}$ environmental impacts, the optimised tailored diets showed reductions per MJ NE of feed for GWP (- 12.8\% and - 4.5\% for the HRFI optimised tailored diet and LRFI optimised tailored diet, respectively), LO ( $-18.6 \%$ and $-27.4 \%)$, AP $(-5.2 \%$ for HRFI), and increased in EP $(+3.1 \%$ for LRFI) and EP (+ $40.7 \%$ and $+8.4 \%)$. The price of optimised tailored diets $(0.199 € / \mathrm{kg}$ for LRFI and $0.208 € / \mathrm{kg}$ HRFI) was lower than the price of the conventional diet $(0.234 € / \mathrm{kg})$ per $\mathrm{kg}$ of feed and per MJ of NE. These feed prices were less than $110 \%$ of the least cost diets prices of each line.
Table 2 Mean maximum individual standardised requirements for the low residual feed intake (LRFI) line and the high residual feed intake (HRFI) line and their standard deviations $(N=57$ pigs per line)

\begin{tabular}{lrrr}
\hline & \multicolumn{1}{l}{ LRFI } & \multicolumn{1}{l}{ HRFI } & \multicolumn{1}{l}{$P$} \\
\hline Alpha: digestible crude protein requirement (g/MJ NE) & $11.75(2.46)$ & $11.04(2.33)$ & $<0.05$ \\
Beta: digestible lysine requirement (g/MJ NE) & $0.91(0.20)$ & $0.86(0.18)$ & $<0.05$ \\
Gamma: digestible threonine requirement (g/MJ NE) & $0.58(0.12)$ & $0.55(0.11)$ & $<0.05$ \\
Lambda: digestible methionine requirement (g/MJ NE) & $0.27(0.03)$ & $0.26(0.05)$ & $<0.05$ \\
Delta: digestible tryptophan requirement (g/MJ NE) & $0.16(0.06)$ & $0.15(0.03)$ & $<0.05$ \\
\hline
\end{tabular}


Table 3 Environmental impacts of $1 \mathrm{~kg}$ of the conventional, optimised tailored diet (OTD) and least cost diets for the low residual feed intake (LRFI) line and the high RFI (HRFI) line

\begin{tabular}{|c|c|c|c|c|c|c|c|}
\hline & $\mathrm{GWP}\left(\mathrm{kg} \mathrm{CO}_{2} \mathrm{eq}\right)$ & $\mathrm{AP}\left(\mathrm{g} \mathrm{SO}_{2} \mathrm{eq}\right)$ & $\mathrm{EP}(\mathrm{g}$ P eq) & LO ( $\mathrm{m}^{2}$ a crop eq) & $\mathrm{EI}_{\text {score }}$ & Price $(€)$ & $\mathrm{NE}(\mathrm{MJ})$ \\
\hline \multicolumn{8}{|l|}{$/ \mathrm{kg}$ feed } \\
\hline LRFI OTD & 0.456 & 6.64 & 0.43 & 1.27 & 3.68 & 0.199 & 9.38 \\
\hline LRFI least cost diet & 0.504 & 5.71 & 0.49 & 1.69 & 4.00 & 0.187 & 9.30 \\
\hline HRFI OTD & 0.433 & 6.34 & 0.58 & 1.48 & 3.85 & 0.208 & 9.78 \\
\hline HRFI least cost diet & 0.484 & 6.84 & 0.60 & 1.42 & 4.00 & 0.204 & 10.01 \\
\hline Conventional diet & 0.494 & 6.66 & 0.41 & 1.81 & 4.04 & 0.234 & 9.70 \\
\hline \multicolumn{8}{|l|}{ /MJ NE } \\
\hline LRFI OTD & 0.0486 & 0.707 & 0.0458 & 0.135 & 0.392 & 0.0212 & \\
\hline LRFI least cost diet & 0.0541 & 0.613 & 0.0526 & 0.181 & 0.430 & 0.0201 & \\
\hline HRFI OTD & 0.0442 & 0.648 & 0.0593 & 0.151 & 0.393 & 0.0213 & \\
\hline HRFI least cost diet & 0.0483 & 0.683 & 0.0599 & 0.141 & 0.399 & 0.0203 & \\
\hline Conventional diet & 0.0509 & 0.686 & 0.0422 & 0.186 & 0.416 & 0.0241 & \\
\hline
\end{tabular}

The difference in percentage between the low residual feed intake line (LRFI) and the high RFI (HRFI) line optimised tailored diets (OTDs) with conventional diet standardised to their net energy (NE)

$P$ phosphorous, $m^{2}$ a crop eq area time, $E I_{\text {score }}$ environmental impact score obtained from normalized impacts to the least cost diet combined additively with a weigh of one

\subsection{Sensitivity analysis of the environmental impacts of the diets to the representative requirements of the lines and weighting factors}

To evaluate the sensitivity of the optimised tailored diet environmental impacts to the changes in representative requirements of the lines, a sensitivity analysis was performed by changing all the requirements by +1 or $-1 \mathrm{SD}$ at once. The percentage changes in the environmental impacts and the environmental score of the new optimised tailored diets (details on composition are provided in Supplementary Material S3) are shown in Fig. 2. All environmental impacts increased after increasing the representative requirements of the lines by $+1 \mathrm{SD}$ in the two lines, except AP for LRFI line and EP for HRFI. Changes in the HRFI line were more than $5 \%$ for all environmental impacts with the exception of AP (+ 4\%), whereas sensitivity was much higher for the LRFI optimised tailored diet, with marked increases in LO and $\mathrm{EP}(>+35 \%)$. On the other hand, decreasing all the representative requirements of the lines by $1 \mathrm{SD}$ led to moderate

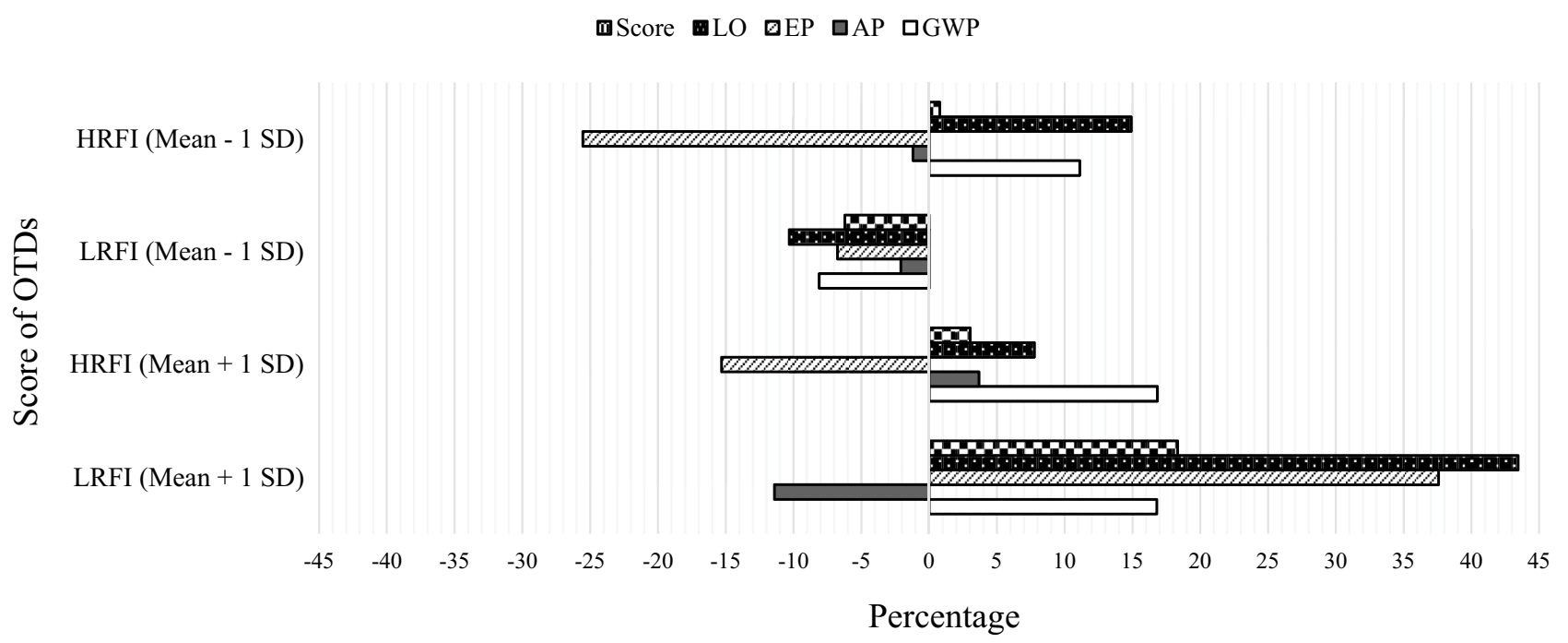

Fig. 2 Percentage changes in the environmental impacts and score of the optimised tailored diets for the high residual feed intake (HRFI) line and the low residual feed intake (LRFI) line when the representative requirements of the lines are changed by $\pm 1 \mathrm{SD}$ all-at-once in the diet-optimised formulation. GWP global warming potential, AP acidification potential, EP freshwater eutrophication potential, LO land occupation 
changes in the environmental impact of the line optimised tailored diets. HRFI optimised tailored diet had increased GWP and LO after reduction of the requirements $(>+11 \%)$, and decreased EP $(-25 \%)$, whereas all environmental impacts were reduced for the LRFI optimised tailored diet when - 1SD was applied to the requirements, from 6 (EP) to $10 \%$ (LO), with very limited change in AP. Based on these sensitivity results, GWP, EP and LO were most sensitive to the changes in requirements. The environmental scores were affected by the changes in requirements mainly in the LRFI line, with a decrease of $6.2 \%$ when the requirements were reduced and an increase by $18 \%$ when they were increased.

To evaluate the sensitivity of the optimised tailored diet score to variations of environmental impact weights, a oneat-a-time sensitivity analysis was performed (Fig. 3). Altogether, the sensitivity of the optimised tailored diet environmental score to the score weight changes was relatively low, and only found for LRFI optimised tailored diet: the main sensitivity was found for increases in the LRFI optimised tailored diet scores in relation to LO, EP and AP reduced weights (increases $>6 \%$ ), and LRFI optimised tailored diet scores when the weights for AP and GWP were increased.

\subsection{Simulated individual trait responses to the line optimised tailored diets}

The performance responses of all individual pigs to the line optimised tailored diets were simulated with InraPorc ${ }^{\circledR}$ up to the $120 \mathrm{~kg} \mathrm{BW}$. Table 4 gives the resulting mean and SD of the performance traits for each line. Significant differences between the lines were observed for feed intake $(P<0.05)$,
Table 4 Mean and standard deviation (SD) of growth performance traits and body composition for the low residual feed intake (LRFI) line and high residual feed intake (HRFI) line fed their corresponding optimised tailored diet, simulated by InraPorc ${ }^{\circledR}$

\begin{tabular}{lccccc}
\hline Traits & Mean & Mean & SD & SD & $P^{1}$ \\
& LRFI & HRFI & LRFI & HRFI & \\
\hline ADG fattening (kg/day) & 0.78 & 0.81 & 0.09 & 0.07 & 0.061 \\
ADFI fattening (kg/day) & 2.04 & 2.13 & 0.21 & 0.16 & $<0.05$ \\
FCR fattening (kg/kg & 2.61 & 2.64 & 0.19 & 0.18 & 0.55 \\
$\quad$ gain) & & & & & \\
ECR fattening (MJ/kg & 24.56 & 25.84 & 1.81 & 1.77 & $<0.001$ \\
$\quad$ gain) & & & & & \\
Fattening duration (days) & 119.5 & 112.9 & 16.3 & 11.8 & $<0.05$ \\
BW slaughter (kg) & 121.37 & 121.26 & 0.43 & 0.43 & 0.34 \\
Age slaughter (days) & 191.05 & 185.12 & 15.26 & 11.36 & $<0.05$ \\
PD fattening (g/day) & 127.8 & 128.2 & 14.0 & 11.3 & 0.76 \\
BL (kg) & 24.70 & 28.08 & 3.09 & 2.65 & $<0.0001$ \\
BFT slaughter (mm) & 16.20 & 17.50 & 1.15 & 0.99 & $<0.0001$ \\
BP (kg) & 19.38 & 18.89 & 0.44 & 0.37 & $<0.0001$ \\
BP/BL at slaughter & 0.79 & 0.68 & 0.11 & 0.07 & $<0.0001$ \\
\hline
\end{tabular}

$B W$ body weight, $A D G$ average daily gain, $A D F I$ average daily feed intake, $F C R$ feed conversion ratio, $E C R$ energy conversion ratio, $P D$ protein deposition, $B F T$ back fat thickness, $B P / B L$ ratio of body protein weight/body lipid weight at slaughter, $B P$ body protein content, $B L$ body lipid content

${ }^{1} P$ were calculated via a t-test on the line effect

energy conversion ratio $(P<0.001)$, protein weight at slaughter $(P<0.0001)$, backfat thickness $(P<0.0001)$, body lipids at slaughter $(P<0.0001)$, with lower average values in the LRFI line, and age at slaughter $(P<0.05)$ and ratio body

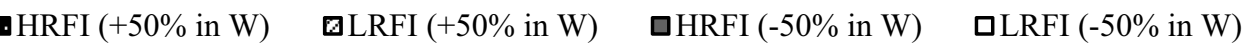

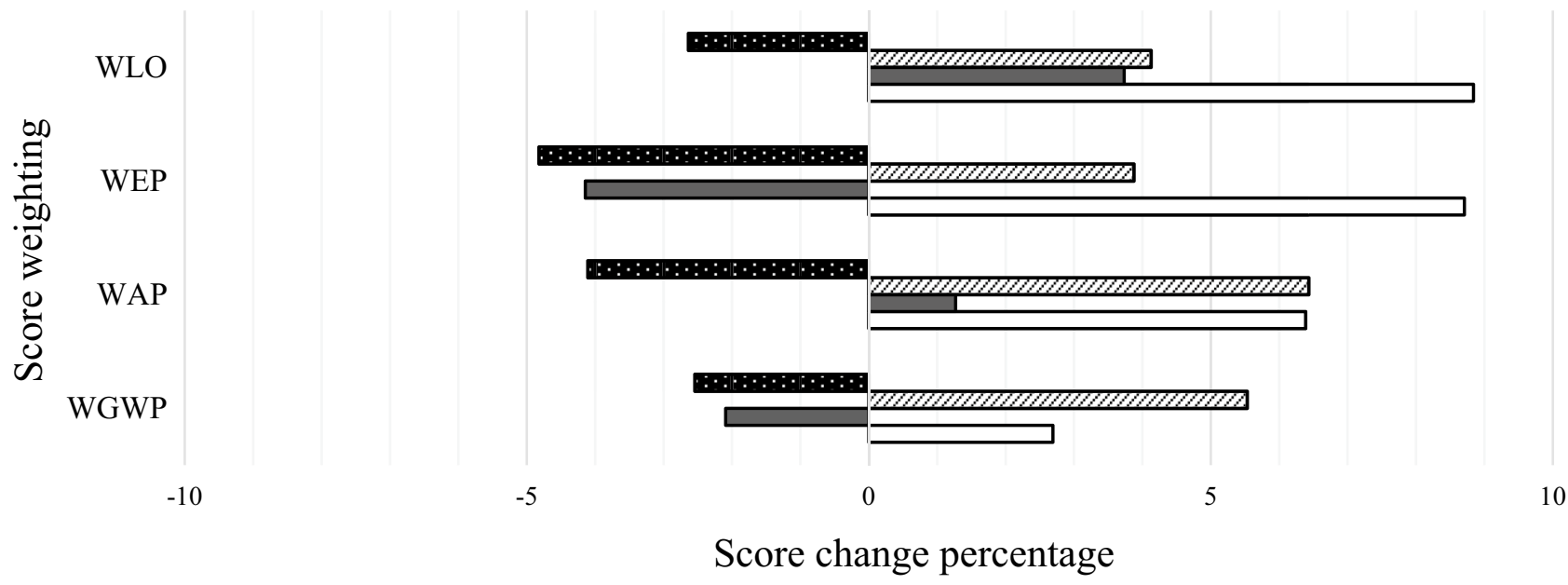

Fig. 3 Percentage changes in the environmental score of the optimised tailored diets of the high residual feed intake (HRFI) line and the low residual feed intake (LRFI) line when the weights (wGWP, wEP, wAP and wLO) were changed by $\pm 50 \%$ one-at-a-time for the diet-optimised formulation. wGWP weight for global warming potential, wEP weight acidification potential, wEP weight fresh water eutrophication potential, wLO weight land occupation 
Table 5 Mean and standard deviation (SD) of four environmental impact categories calculated per kg of body weight of pig at the farm gate (120 kg body weight) through individual LCA using the ReCiPe
2016 Midpoint $(\mathrm{H})$ V1.13 method for the low residual feed intake (LRFI) line and the high residual feed intake (HRFI) line fed their optimised tailored diet (OTDs) and conventional diet (Con)

\begin{tabular}{|c|c|c|c|c|c|c|c|c|c|c|c|}
\hline Impact category & Unit & $\begin{array}{l}\text { Mean } \\
\text { LRFI } \\
\text { OTD }\end{array}$ & $\begin{array}{l}\text { Mean } \\
\text { HRFI } \\
\text { OTD }\end{array}$ & $\begin{array}{l}\text { SD } \\
\text { LRFI } \\
\text { OTD }\end{array}$ & $\begin{array}{l}\text { SD } \\
\text { HRFI } \\
\text { OTD }\end{array}$ & $\begin{array}{l}P^{1} \\
\text { OTDS }\end{array}$ & $\begin{array}{l}\text { Mean } \\
\text { HRFI } \\
\text { Con }\end{array}$ & $\begin{array}{l}\text { Mean } \\
\text { LRFI Con }\end{array}$ & $\begin{array}{l}\text { SD } \\
\text { LRFI } \\
\text { Con }\end{array}$ & $\begin{array}{l}\text { SD } \\
\text { HRFI } \\
\text { Con }\end{array}$ & $\begin{array}{l}P^{1} \\
\text { Con }\end{array}$ \\
\hline Global warming potential & $\mathrm{kg} \mathrm{CO}_{2}$ eq & 1.96 & 2.00 & 0.098 & 0.092 & $<0.05$ & 2.21 & 2.07 & 0.124 & 0.124 & $<0.0001$ \\
\hline Acidification & $\mathrm{g} \mathrm{SO}_{2} \mathrm{eq}$ & 35.6 & 36.5 & 2.37 & 2.22 & $<0.05$ & 40.0 & 36.8 & 2.783 & 2.797 & $<0.0001$ \\
\hline Eutrophication & g P eq & 1.27 & 1.39 & 0.077 & 0.081 & $<0.0001$ & 1.24 & 1.16 & 0.077 & 0.077 & $<0.0001$ \\
\hline Land occupation & $\mathrm{m}^{2} \mathrm{a}$ crop eq & 3.53 & 4.17 & 0.21 & 0.24 & $<0.0001$ & 4.58 & 4.30 & 0.30 & 0.30 & $<0.0001$ \\
\hline
\end{tabular}

$P$ phosphorous, $m^{2}$ a crop eq area time

${ }^{1} P$ were calculated via a $t$ test on the line effect

proteins/body lipids at slaughter $(P<0.0001)$, with higher values in the LRFI line.

\subsection{Environmental assessment of the overall farm feed efficiency approach}

To assess the environmental impacts of producing $1 \mathrm{~kg}$ of live pig through feeding the line optimised tailored diets, an individual LCA was performed in SimaPro for each pig fed its line optimised tailored diet, based on the performance traits simulated with InraPorc ${ }^{\circledR}$. Table 5 lists the resulting four impact categories for the two lines. In response to their optimised tailored diet, all impact categories differed significantly $(P<0.05)$ between lines, the HRFI line having systematically larger impacts than the LRFI line (from +2.04 for GWP to $+18.13 \%$ for LO). The lines with the conventional diet differed significantly in all impact categories $(P<0.0001)$, with a minimum difference in LO $(+6.5 \%)$ and maximum difference in AP $(+8.7 \%)$ in HRFI relative to LRFI (Table 5). The environmental impacts of the lines fed their optimised tailored diets are shown together with their environmental impacts with the conventional diet in Fig. 4, with reference to the scenario with least environmental impacts (LRFI line fed its optimised tailored diet). Feeding the lines with their optimised tailored diets reduced all environmental impacts compared to when fed

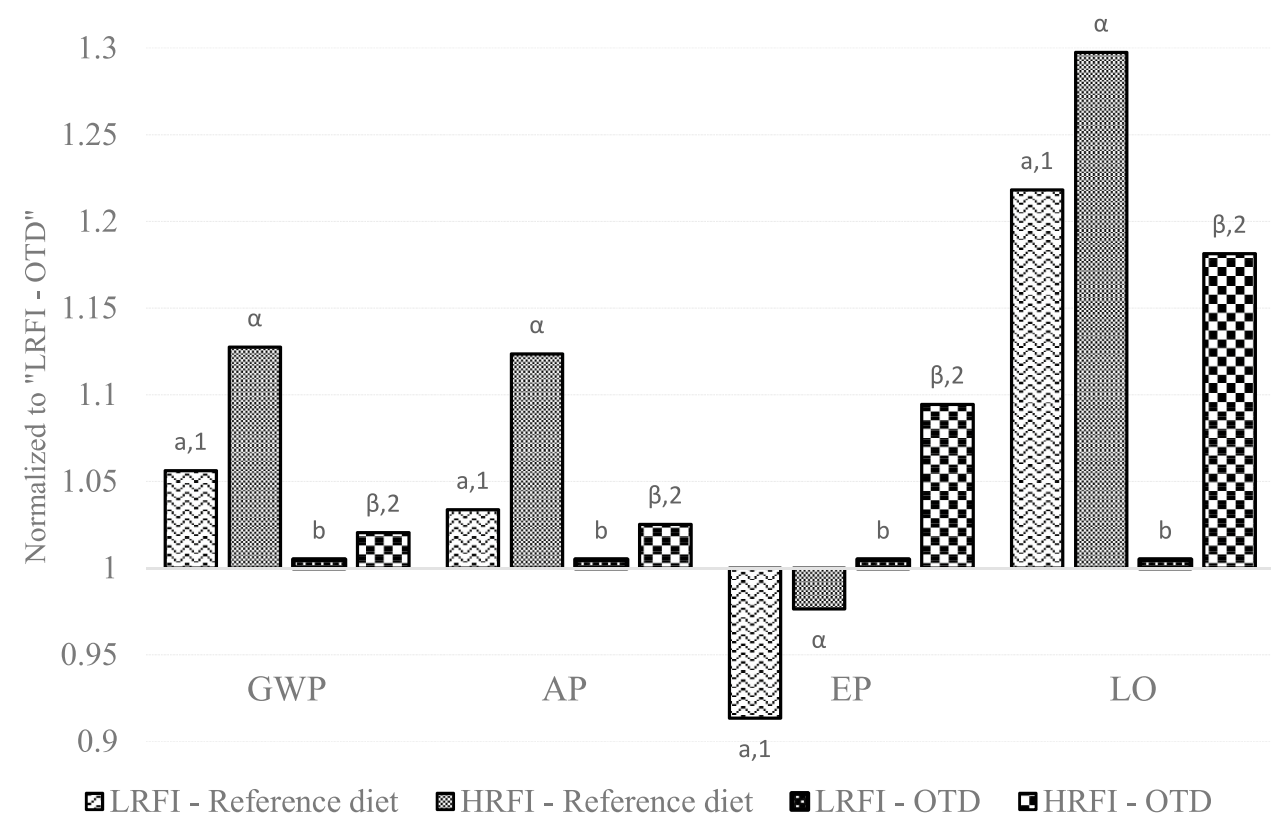

Fig. 4 Four environmental impact categories for the low residual feed intake (LRFI) line and high residual feed intake (HRFI) line fed their optimised tailored diet (OTD) and the conventional diet, presented relative to the impacts of the LRFI line fed its OTD. GWP global warming potential, AP acidification potential, EP freshwater eutrophication potential, LO land occupation. ${ }^{1}$ For each impact category, different superscripts in Latin letters indicate significant differences at $P<0.05$ for pair- wise $t$ test comparisons of impacts of the LRFI line fed different diets; different superscripts in Greek letters indicate significant differences at $P<0.05$ for pairwise $t$ test comparisons of impacts of the HRFI line fed different diets; different number superscripts indicate significant differences at $P<0.05$ for pairwise $t$ test comparisons of impacts of the LRFI line fed the conventional diet and the HRFI line fed the OTD 
the conventional diet $(P<0.0001)$, with the exception of EP which increased $(P<0.0001)$. For all environmental impact categories, a bigger decrease was found with the line optimised tailored diet for the HRFI genetic line than the LRFI genetic line, with the exception of LO, which remained quite high. Altogether, feeding the HRFI line its optimised tailored diet led to a scenario with less environmental impacts than the LRFI line fed the conventional diet, with the exception of EP.

\subsection{Correlations between growth performance traits and impact categories}

To gain more insight into the relationships between growth performance traits and environmental impacts when the lines where fed their optimised tailored diet, phenotypic correlations were computed between the individual performances and the individual LCA results in each line fed its own optimised tailored diet (Supplementary Material S4). According to the $95 \%$ confidence interval of the correlation estimations, no difference between lines could be inferred for these correlations, except for RFI whose correlation with environmental impacts was 0.49 in the LRFI line, whereas it was 0.11 in the HRFI line. A principal component analysis (PCA) was performed to illustrate these correlations between traits and environmental impacts. Figure 5 shows the projection of the traits and EIs on the two first dimensions. All the impact categories were highly correlated with FCR, with correlations higher than 0.82 , driving the first dimension of the PCA. Impact categories also had moderate to high negative correlations with traits related to protein deposition $\mathrm{BP} / \mathrm{BL}$ ratio, $\mathrm{BP}, \mathrm{PD}$ and $\mathrm{ADG}$, with the absolute values higher than 0.42 for both lines.

\section{Discussion}

In this study, the reduction of environmental impacts of pig production due to improvement in overall farm feed efficiency was assessed through LCA. Genetic selection for feed efficiency, formulation of diet tailored to each line, and environmental diet optimisation were combined to achieve better production efficiency with reduced environmental impacts.

\subsection{Environmental assessment of overall farm feed efficiency}

Performing individual LCA on the two genetic lines of pigs fed their optimised tailored diet markedly improved the environmental score, demonstrating the value of the overall farm feed efficiency approach for environmental optimisation of pig production. In this study, the objective
Fig. 5 Projection of the traits and environmental impacts (EI) on the two first dimensions of a principal component analysis applied to the correlation matrix between and the environmental impacts and the traits after adjustment for the line effect $(N=114$ pigs with data). DUR duration, ADFI average daily feed intake, ADG average daily gain, BP body protein at slaughter, BP.BL ratio of body protein-to-body lipid at slaughter, PD average daily protein deposition, BFT back fat thickness, FCR feed conversion ratio, $\mathrm{RFI}$ residual feed intake, $\mathrm{BL}$ body lipid content at slaughter, GWP global warming potential, $\mathrm{AP}$ acidification potential, EP freshwater eutrophication potential, LO land occupation

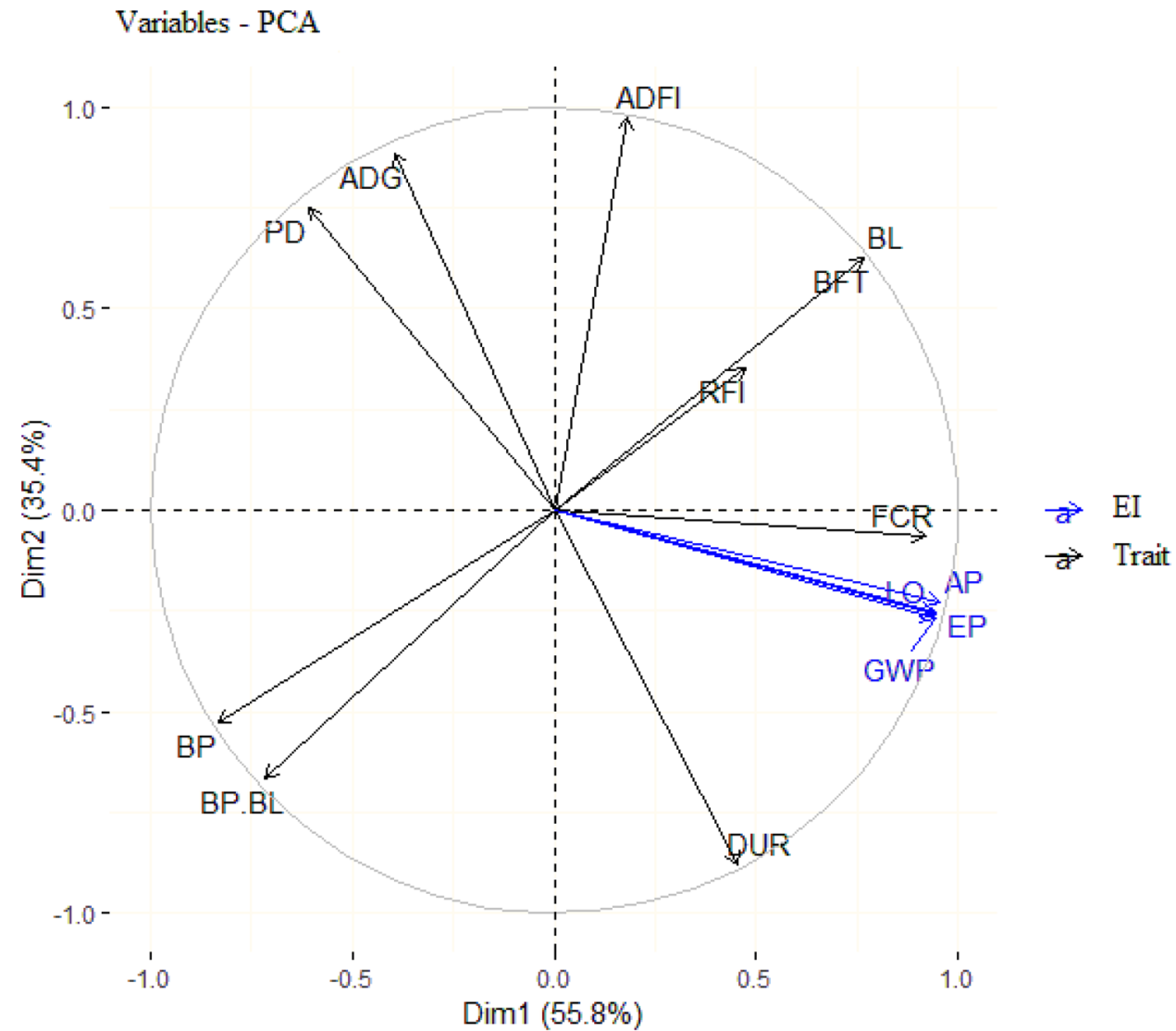


was to demonstrate that optimized combinations of genetics and diets are a path to reduce the environmental burden of pig production. From this simulation study, changes in the assumptions and conditions of the model could affect the outcomes of each scenario. However, most deviations from the current assumptions would have a similar effect for all the compared scenarios. For instance, it is expected that variations in the supply chain of the ingredients (e.g. origin), database inventories, manure management and application, farm operations, pig survival rate, and other methodological choices would modify the magnitude of the impacts for all scenarios, while the general conclusions about the scenario differences would hold robust. The results of this study are limited to the simulation tools and further field studies will be required to confirm these outcomes. With weights of 1 for the four impact categories in the environmental score and our list of ingredients, the lines fed their optimised tailored diet had lower GWP, AP and LO than the lines fed a single conventional diet, but not higher EP. Since the phosphorous content of the optimised tailored diets was lower than in the conventional diet, the increased EP in the two lines could be explained by the higher EP of the optimised tailored diet, via higher EP of their ingredients, rather than by increased excretion and leaching of phosphorous during manure storage and spreading. The substitution of the synthetic fertilisers by the $\mathrm{N}, \mathrm{P}$ and $\mathrm{K}$ of the manure has partly alleviated the environmental burdens of the pig production. The differences in environmental impacts between the LRFI and HRFI lines fed their optimised tailored diet were smaller than the differences when they were fed the conventional diet, even if only a limited list of ingredients to be incorporated was considered in our study. Including a larger variety of ingredients, for instance with lower environmental impacts and lower amino acid concentrations relative to NE, as HRFI pigs had lower representative requirements, could further limit the environmental impacts of the less efficient pigs in a population. Furthermore, as previously reported by Soleimani and Gilbert (2020) with the same model applied to the lines fed the conventional diet, correlations between performance traits and environmental impacts appear to be robust to changes in the animals' genetic potential, and the present study shows that they are also robust to the diet. Thus, the high correlations between all environmental impacts and FCR and protein deposition related traits make them good candidates for the definition of an environmentally oriented selection index.

\subsection{Formulation of diets tailored to each line and environmental multiobjective optimisation}

A number of studies have been dedicated to optimising diets to achieve different objective functions. Pomar and Pomar (2012) considered the reduction in $\mathrm{N}$ and $\mathrm{P}$ excretions as the objective function, and Nguyen et al. (2012) targeted cost as the objective function, and GWP and EP as the constraints.
Tallentire et al. (2017) minimised a single impact as the objective function along with the constraint of limiting the increase in the cost of the diet compared to a least cost diet. Mackenzie et al. (2016) included four environmental impact categories in their objective function, and combined predictions of excretion corresponding to each dietary nutrient. Finally, Garcia-Launay et al. (2018) presented a multiobjective formulation method to include feed costs and environmental impacts in the objective function using weighting factors. In our study, we capitalised on these approaches to implement a multi-objective diet formulation combining environment, cost and line nutritional requirements. More specifically, the choice of an environmental score is critical, along with the choice of which environmental impacts to include, the choice of normalization factors to standardise the magnitude of the environmental impacts in the score, and the choice of weights to combine them. First, the four highest environmental impacts at the pig production level were retained. Energy demand for instance, as one of the main impacts of diet productions, could be added to the model later (Basset-Mens et al. 2005; Leinonen et al. 2012). Second, we normalized the diet impacts to the environmental impacts of the least cost diet for each line (Garcia-Launay et al. 2018), so all environmental scores can be interpreted with respect to this reference. Third, equal weights were considered for all impact categories in the definition of the environmental score to minimise (Mackenzie et al. 2016). Diet optimisation for a single environmental impact may increase other impact categories (Tallentire et al. 2017). Giving equal weights is an arbitrary choice, and, depending on the societal context and on the load of the different impacts on the territory, different weights could be applied. However, the sensitivity analysis results showed that changes in the environmental impact score are difficult to predict when the weights are modified, as previously reported by GarciaLaunay et al. (2018): a higher value for a given weighting factor does not ensure a major reduction in the intended impact, and may increase other impacts. Finally, rather than considering the estimated emissions and excretions after diet consumption in the diet optimisation (Mackenzie et al. 2016), our formulation approach was constrained to the NE content of the resulting diet. This choice ensures consistency with the expected intakes, and hence related emissions and excretions at the pig farm level. Simultaneously minimising the environmental impacts and constraining cost is a multiobjective optimisation problem, with the issue of having a different scale for each objective. Different approaches have been proposed to solve this problem in the context of combining environmental impacts and costs, such as monetising the environmental impacts to combine all objectives in a cost function (Eldh et al. 2006), or normalizing the impacts, and weighting them in a single score (Mackenzie et al. 2016). To avoid assumptions on the costs of the different environmen- 
tal impacts, we chose the second option in this study, and combined it with a constraint on the increase in cost. Environmental diet optimisation can increase the cost of the diet, which is the biggest production cost for owners of pig farms. Relative to the conventional diet, the optimised tailored diets cost less and had lower environmental impact scores, per $\mathrm{kg}$ of feed and per unit of NE. However, minimising the environmental impacts had a cost at the level of the diet, which in our study was higher for the HRFI optimised tailored diet than for the LRFI optimised tailored diet. Increasing the number of ingredients, and diversifying them towards incorporation of by-products, would certainly provide more flexibility in the diet optimisation and minimisation of environmental impacts. However since the main concern of the study was to develop and demonstrate the approach towards overall farm feed efficiency, a limited number of new ingredients was tested. In addition to the environmental assessment of overall farm feed efficiency strategies proposed in this study, further economic assessments would be needed to provide complementary insights into their sustainability.

\subsection{Choice of nutritional requirements for each line and performance responses of individual pigs to their optimised tailored diet}

The representative requirements of the LRFI were higher than those of the HRFI, as previously reported by Gilbert et al. (2017) for the same genetic lines. Respecting the high correlations between the five representative requirements, the all-at-once sensitivity analysis showed that environmental impacts were quite sensitive to representative requirements, especially when they were increased by $+1 \mathrm{SD}$. Due to switches between ingredients to respond to the new requirements, the effects on the environmental impacts were quite varied, both in direction and magnitude. However, when summed in the environmental score, the main changes were changes in LRFI representative requirements. The higher baseline requirements for LRFI might reflect the higher sensitivity of impacts to higher requirements and underlines the need to adequately capture the nutritional requirements of the targeted animals.

The performance traits showed a decrease in growth rate in both lines with the optimised tailored diets compared to the conventional diet (Soleimani and Gilbert 2020), leading to approximately three more days required for the pigs to reach $120 \mathrm{~kg} \mathrm{BW}$. This is certainly related to the choice of representative requirements to formulate the line constraints: considering the average maximum nutritional requirements in each line would lead to the nonsatisfaction of the requirements in about half the animals in the early stage of the growing phase. In our dataset, this was limited to the very first days of the growing period, but could create a longer delay in reaching slaughter body weight.
In an environmental perspective, the reduction in growth rate could be considered to be offset by the reduction in the environmental impacts to produce $1 \mathrm{~kg}$ of live pig in both lines. One possible way to alleviate this reduction in growth performance would be to increase the representative requirements, considering the $75 \%$ quantile of the maximum pig requirements per line, rather than the average maximum. Increased environmental impacts would certainly result from this strategy, especially in the more efficient genetic line, as shown by the sensitivity analysis. However, this could be reduced by formulating optimised tailored diets for different growth stages using multiphase feeding. In addition, individually tailored diet formulation and optimisation would certainly offer higher overall farm feed efficiency through precision feeding of individual pigs (Pomar and Remus 2019) selected for feed efficiency. However, a further economic assessment would reveal to what extent cost is compromised by switching from a conventional diet to optimised tailored diets at the farm level.

\section{Conclusion}

Animal selection for feed efficiency, formulation of diets tailored to the requirements of a genetic line, and environmental optimisation of the diet have separate potential for improving farm feed efficiency to reduce environmental impacts. Our study shows that combining these levers in an overall farm feed efficiency approach would remarkably reduce the environmental impacts of pig production systems. The real-time diet formulation tailored to the requirements of each individual selected for feed efficiency, integrated in real time optimisation according to an objective or multi-objective environmental function, would be a complementary tool to mitigate the environmental impacts of pig production. Although environmental optimisation of the production system was achieved in our study, economic evaluations of the full production system including different ranges of genetic and dietary options will be necessary to achieve selection and formulation decisions that tackle the necessary trade-offs between economic and environmental objectives of a sustainable pig production system.

Supplementary Information The online version contains supplementary material available at https://doi.org/10.1007/s11367-020-01860-3.

Acknowledgements This study is part of a collaborative project supported by the ERA-NET SUSAN programme via the ANR16-SUSN-0005 contract (SusPig). The authors are grateful to the experimental farm UE GenESI (INRAE, Surgères, France) for animal care and data collection as well as InraPorc ${ }^{\circledR}$ developers. The authors would like to thank Dr. Garcia- Launay and Prof. Ilias Kyriazakis for the valuable comments and recommendations on this study. 


\section{Compliance with ethical standards}

Conflict of interest The authors declare that they have no conflict of interest.

Open Access This article is licensed under a Creative Commons Attribution 4.0 International License, which permits use, sharing, adaptation, distribution and reproduction in any medium or format, as long as you give appropriate credit to the original author(s) and the source, provide a link to the Creative Commons licence, and indicate if changes were made. The images or other third party material in this article are included in the article's Creative Commons licence, unless indicated otherwise in a credit line to the material. If material is not included in the article's Creative Commons licence and your intended use is not permitted by statutory regulation or exceeds the permitted use, you will need to obtain permission directly from the copyright holder. To view a copy of this licence, visit http://creativecommons.org/licenses/by/4.0/.

\section{References}

Basset-Mens C, van der Werf HMG (2005) Scenario-based environmental assessment of farming systems: the case of pig production in France. Agric Ecosyst Environ 105:127-144

Brossard L, Taoussi I, van Milgen J, Dourmad JY (2017) Selection of methods to analyse body weight and feed intake data used as inputs for nutritional models and precision feeding in pigs. 8. European Conference on Precision Livestock Farming (ECPLF), Nantes, France. Hal-01591146

Brossard L, Marcon M, Dourmad JY, van Milgen J, Pomar J, Lopez V, Quiniou N (2019) Application of a precision feeding program in growing pigs: effect on performance and nutrient use. $70^{\text {th }}$ Annual meeting of the EAAP, 26-30 August 2019, Ghent, Belgium

Cadéro A, Aubry A, Brossard L, Dourmad JY, Salaün Y, GarciaLaunay F (2018) Modelling interactions between farmer practices and fattening pig performances with an individual-based model. Anim Sci J 12:1277-1286

Cai W, Casey DS, Dekkers JCM (2008) Selection response and genetic parameters for residual feed intake in Yorkshire swine. Anim Sci J 86:287-298

D'Mello JPF (1993) Amino acid supplementation of cereal-based diets for non-ruminants. Anim Feed Sci Technol https://doi.org/ 10.1016/0377-8401(93)90068-U

de Vries M, de Boer IJM (2010) Comparing environmental impacts for livestock products: A review of life cycle assessments. Livest Sci 128:1-11

Dourmad Etienne JYM, Valancogne A, Dubois S, van Milgen J, Noblet J (2008) InraPorc ${ }^{\circledR}$ : a model and decision support tool for the nutrition of sows. Anim Feed Sci Technol 143:372-386

Dourmad JY, Jondreville C (2007) Impact of nutrition on nitrogen, phosphorous, $\mathrm{Cu}$ and $\mathrm{Zn}$ in pig manure, and on emission of ammonia and odours. Livest Sci 112:192-198

Eldh P, Johansson J (2006) Weighting in LCA Based on Ecotaxes Development of a Mid-point Method and Experiences from Case Studies. Int J Life Cycle Assess 11:81-88

Garcia-Launay F, van der Werf HMG, Nguyen TTH, Le Tutour L, Dourmad JY (2014) Evaluation of the environmental implications of the incorporation of feed-use amino acids in pig production using Life Cycle Assessment. Livest Sci 161:158-175

Garcia-Launay F, Dusart L, Espagnol S, Laisse-Redoux S, Gaudré D, Méda B, Wilfart A (2018) Multi objective formulation is an effective method to reduce environmental impacts of livestock feeds. Br J Nutr 120:1298-1309
Gilbert H, Bidanel JP, Gruand J, Caritez JC, Billon Y, Guillouet P, Lagant H, Noblet J, Sellier P (2007) Genetic parameters for residual feed intake in growing pigs, with emphasis on genetic relationships with carcass and meat quality traits. Anim Sci J 85:3182-3188

Gilbert H, Bidanel JP, Billon Y, Lagant H, Guillouet P, Sellier P, Noblet J, Hermesch S (2012) Correlated responses in sow appetite, residual feed intake, body composition, and reproduction after divergent selection for residual feed intake in the growing pig. Anim Sci J 90:1097-1108

Gilbert H, Billon Y, Brossard L, Faure J, Gatellier P, Gondret F, Labussière E, Lebret B, Lefaucheur L, Le Floch N, Louveau I, Merlot E, Meunier-Salaün MC, Montagne L, Mormede P, Renaudeau D, Riquet J, Rogel-Gaillard C, van Milgen J, Vincent A, Noblet J (2017) Review: divergent selection for residual feed intake in the growing pig. Anim Sci J 11:1427-1439

Hauschild L, Lovatto PA, Pomar J, Pomar C (2012) Development of sustainable precision farming systems for swine: estimating realtime individual amino acid requirements in growing-finishing pigs. Anim Sci J 90:2255-2263

Huijbregts MAJ, Steinmann ZJN, Elshout PMF, Stam G, Verones F, Vieira MDM, Hollander A, Zijp M, van Zelm R (2017) ReCiPe 2016: a harmonized life cycle impact assessment method at midpoint and enpoint level. Int J Life Cycle Assess 22:138-147

IFIP 2020, Institut du porc. France. www.ifip.asso.fr

IFIP-Institut de la Filière porcine 2014. http://ifip.asso.fr

IPCC 2006. Intergovernmental Panel on Climate Change (IPCC) 2006. 2006 IPCC guidelines for national greenhouse gas inventories (ed. Eggleston HS, Buendia L,Miwa K, Ngara T and Tanabe K), pp. 1-87. Volume 4-Agriculture, Forestry and Other Land Use, Chapter 10-Emissions from Livestock and Manure Management. IGES, Japan.

Itskos G, Nikolopoulos N, Kourkoumpas DS, Koutsianos A, Violidakis I, Drosatos P, Grammelis P (2016) Energy and the Environment Basic Principles, Human Activities, and Environmental Implications, chapter 6 - pp 363-452

Lammers PJ (2011) Life-cycle assessment of farrow-to-finish pig production systems: a review. Anim Sci J Reviews 6:1749-8848

Leinonen I, Williams AG, Wiseman J, Guy J, Kyriazakis I (2012) Predicting the environmental impacts of chicken systems in the United Kingdom through a life cycle assessment: egg production systems. Poult Sci J 91:26-40

Mackenzie SG, Leinonen I, Ferguson N, Kyriazakis I (2015) Accounting for uncertainty in the quantification of the environmental impacts of Canadian pig farming systems. Anim Sci J 93:3130-3143

MacKenzie SG, Leinonen I, Ferguson N, Kyriazakis I (2016) Towards a methodology to formulate sustainable diets for livestock: accounting for environmental impact in diet formulation. Br J Nutr 115:1860-1874

McAuliffe GA, Chapman DV, Sage CL (2016) A thematic review of life cycle assessment (LCA) applied to pig production. Environ Impact Assess Rev 56:12-22

McAuliffe GA, Takahashi T, Mogensen L et al (2017) Environmental trade-offs of pig production systems under varied operational efficiencies. J Clean Prod 165:1163-1173

Monteiro AR, Garcia-Launay F, Brossard L, Wilfart A, Dourmad JY (2017) Effect of precision feeding on environmental impact of fattening pig production. European Conference on Precision Livestock Farming (ECPLF), Nantes, France. Hal-01591143

Nemecek T, Heil A, Huguenin-Elie O et al (2004) Life cycle inventories of agricultural production systems. Final Report Ecoinvent $15: 145-146$

Nguyen T, Hermansen J, Mogensen L (2012) Environmental costs of meat production: The case of typical EU pork production. J Clean Prod 28:168-176 
Nguyen TLT, Hermansen JE, Mogensen L (2010) Fossil energy and GHG saving potentials of pig farming in the EU. Energy Policy 38:2561-2571

Nguyen TLT, Hermansen JE, Mogensen L (2011) Environmental Assessment of Danish Pork. Faculty of Agricultural Sciences, Aarhus University, (31pp) (Internal Report).

Nguyen TLT, Hermansen JE, Mogensen L (2012) Environmental costs of meat production: the case of typical EU pork production. $\mathrm{J}$ Clean Prod 28:168-176

Opio C, Gerber P, Mottet A, Falcucci A, Tempio G, MacLeod M, Vellinga T, Henderson B, Steinfeld H (2013) Greenhouse gas emissions from ruminant supply chains. A global life cycle assessment, Food and Agriculture Organization of the United Nations (FAO), Rome

Ottosen M, Stephen G, Mackenzie SG, Wallace M, Kyriazakis I (2019) A method to estimate the environmental impacts from genetic change in pig production systems. Int J Life Cycle Assess 25:523-537

Pomar C, Hauschild L, Zhang G, Pomar J, Lovatto PA (2009) Applying precision feeding techniques in growing-finishing pig operations. R Bras Zootec 38:226-237

Pomar C, Remus A (2019) Precision pig feeding: a breakthrough toward sustainability. Anim Front 9:52-59

Pomar G, Pomar C (2012) Sustainable precision livestock farming: a vision for the future of the Canadian swine industry 23:207-213

Quiniou N, Noblet J (2012) Effect of the dietary net energy concentration on feed intake and performance of growing-finishing pigs housed individually. Anim Sci J 90:4362-4372

Remus A, Hauschild L, Corrent E, Marie-Pierre Létourneau-Montminy MP, Pomar C (2019) Pigs receiving daily tailored diets using precision-feeding techniques have different threonine requirements than pigs fed in conventional phase-feeding systems. J Anim Sci Biotechnol 10:16
Rigolot C, Espagnol S, Pomar C, Dourmad JY (2010a) Modelling of manure production by pigs and $\mathrm{NH} 3, \mathrm{~N} 2 \mathrm{O}$ and $\mathrm{CH} 4$ emissions. Part I: animal excretion and enteric $\mathrm{CH} 4$, effect of feeding and performance. J Anim Sci 4:1401-1412

Rigolot C, Espagnol S, Robin P, Hassouna M, Béline F, Paillat JM, Dourmad JY (2010b) Modelling of manure production by pigs and $\mathrm{NH} 3, \mathrm{~N} 2 \mathrm{O}$ and CH4 emissions. Part II: effect of animal housing, manure storage and treatment practices. J Anim Sci 4:1413-1424

Rothschild MF, Ruvinsky A (2011) The genetics of the pig, 2nd edn. UK, CABI, Wallingford, p 496

Sauvant D, Perez JM, Tran G (2004) Tables of composition and nutritional value of feed materials. Wageningen Academic Publishers

Soleimani T, Gilbert H (2020) Evaluating the environmental impacts of selection for residual feed intake in pig. Anim Sci J https://doi. org/10.1017/S175173112000138X

Tallentire CW, MacKenzie SG, Kyriazakis I (2017) Environmental impact trade-offs in diet formulation for broiler production systems in the UK and USA. Agr Syst 154:145-156

van Milgen J, Valancogne A, Dubois S, Dourmad JY, Sève B, Noblet J (2008) InraPorc ${ }^{\circledR}$ : a model and decision support tool for the nutrition of growing pigs. Anim Feed Sci Technol 143:387-405

Wernet G, Bauer C, Steubing B, Reinhard J, Moreno-Ruiz E and Weidema B (2016) The ecoinvent database version 3 (part I): overview and methodology. Int J Life Cycle Assess 21(9):1218-1230. Available at: https://doi.org/10.1007/s11367-016-1087-8

Wilfart A, Espagnol S, Dauguet S, Tailleur A, Gac A, Garcia-Launay F (2016) ECOALIM: a dataset of environmental impacts of feed ingredients used in French animal production. PLoS ONE $11: \mathrm{e} 0167343$

Publisher's Note Springer Nature remains neutral with regard to jurisdictional claims in published maps and institutional affiliations. 